Reynolds, F. (1997) Perceived control over menopausal hot

flushes: exploring the correlates of a standardised measure.

Maturitas: Journal of the Climacteric and Postmenopause, 27,

215-221.

\title{
PERCEIVED CONTROL OVER MENOPAUSAL HOT FLUSHES: EXPLORING THE CORRELATES OF A STANDARDISED MEASURE
}

\section{ABSTRACT:}

Objectives: A substantial minority of women report considerable distress during hot flushes. Coping with various chronic health problems has been related to perceived control in previous studies. Hence this study developed a standardised measure to investigate whether perceived control is associated with less distress during menopausal hot flushes.

Method: The study presented a suitably re-worded 15-item scale (the Arthritis Helplessness Index, originally developed by Nicassio et al (1985). Scoring was reversed so that high scores signified greater perceived control. A volunteer sample of 43 women (mean age 51 years) completed the scale together with several further measures. Thirty five women returned 12 month follow-up questionnaires.

Results: the Perceived Control Index (PCl) scores correlated with standardised measures of self-esteem and simple self-ratings (0-100) of perceived control, and remained very stable over 12 months. Self-rated distress during flush episodes was more closely related to perceived control than to more objective factors such as flush frequency and chronicity.

Conclusion: These findings support further investigation into whether subjective coping with flushes may be improved by psychological interventions that enhance perceived control and self-esteem. 


\section{PERCEIVED CONTROL OVER MENOPAUSAL HOT FLUSHES: EXPLORING THE CORRELATES OF A STANDARDISED MEASURE}

\section{Introduction}

Hot flushes affect more than $50 \%$ of peri- and post-menopausal women, and may occur at least sporadically for many years (Hunter 1992; Kronenberg 1990). Flushing appears to be caused by decreasing levels of oestrogen although the triggers of specific flush episodes are unclear (see Ussher 1989 for one discussion). As well as experiencing a transient rise in body temperature, some women report other physical sensations during flushing including noticeable perspiration, palpitations and feelings of breathlessness or faintness (Voda 1981). Such sensations are self-evidently unpleasant, but discomfort during flushes may also be magnified by reactions such as embarrassment and anxiety about loss of control (Hunter \& Liao 1995).

Hormone Replacement Therapy (HRT) usually provides an effective remedy, eliminating hot flushes or at least markedly reducing flush frequency. However, HRT is currently taken on a long-term basis by relatively few women in the UK (about $10 \%$ of mid-life women according to Hunter 1990 ; Hammond 1994). For some it is inappropriate because of a personal or family health history of breast cancer or endometrial cancer. Some women prefer to avoid medicalising their menopause and resist continuous medication for what they regard as a natural process of aging. Others try HRT but soon discontinue in response to side-effects such as breast pain 
and monthly bleeding (Utian 1990). At present, there are few alternative treatments available for women distressed by flushes but unable to persevere with HRT.

Although most women report discomfort during flushing, it is unclear why about 15$20 \%$ experience considerable distress (Hunter 1989). There is some limited evidence that flush distress is more highly related to personality and cognitive factors than objective variables such as flush frequency or duration. Hunter \& Liao (1995) found that women who were more depressed (or anxious) and lower in self-esteem rated their flushes as more problematic. More specifically, women who rated themselves (on a 10-point scale) as higher in control over their flushes tended to regard their flushes as less problematic.

Perceived control has been identified as strongly predictive of coping and adaptation to some chronic illnesses. Studies of individuals with chronic conditions, such as low back pain, tinnitus and arthritis have shown that coping is strongly associated with perceptions of control rather than helplessness ( e.g. Coles \& Hallam 1987; DeVellis \& Blalock 1992; Keefe et al 1989; Smith et al 1994; Tayer et al 1996). Individuals who feel dependent on others to solve their health problems, and who have poor expectations about their ability actively to manage symptoms, typically go on to experience more pain, depression and restriction in daily life (Nicassio et al 1985). It appears that individuals with a strong sense of control are more committed to active coping, will persevere with difficult tasks, are less fearful of failure and less selfblaming when difficulties arise (Skinner 1995). 
Although the menopause is not an 'illness', for some women it heralds a long period of unpredictable and uncomfortable body sensations. The present study sought to establish whether and to what extent perceived control was related to coping or distress during hot flushes.

The study was influenced by the findings of Nicassio et al (1985) who showed that lower perceived control over arthritis (measured on the standardised Arthritis Helplessness Index $\mathrm{AHI}$ ) was associated with depression, lower self-esteem and greater impairment in everyday activities. In addition, measured helplessness was shown to be highly stable over 12 months. The researchers concluded that the AHI scale had high reliability and construct validity and suggested that: (p.467)

"As the experience of helplessness is common to a variety of medical conditions, the AHI may also serve as a general model for the development of tools with which to study helplessness in chronic illness".

For the current study, the author adapted the 15-item AHI (see Appendix 1). Items were re-worded to refer to menopausal hot flushes. The scoring was reversed (compared with the original) so that high scores reflected greater perceived control. Following on from previous work, it was expected that perceived control would be stable over 12 months and would be associated with the following measures:

i) levels of self-reported distress during flushes

ii) self-esteem 
iii) simpler self-ratings of perceived control (0-100 visual analogue scale)

Furthermore, based on the work of Hunter \& Liao (1995), it was expected that perceived control would be more highly related to the above psychological measures than to more 'objective' features of flushing such as frequency and chronicity.

\section{METHOD}

\section{Participants}

The sample comprised 43 women who volunteered to take part in a postal questionnaire study of their current experiences of menopausal hot flushes. They were contacted through a variety of published requests in newspapers and community organisations, rather than through general practitioners, as women currently seeking medical help for menopausal problems tend to be more distressed (Ballinger 1985; Morse et al 1994). A similar recruitment process has been used in other studies that aimed to avoid respondents actively seeking medical help (e.g. Mansfield et al 1992; Tayer et al 1996). Mean age was 51.2 years (range 39- 65 years). Most were living with partners $(75 \%) ; 77 \%$ had children, and nearly half of these $(44 \%)$ reported that at least one was still living at home. Those in paid work (full- or part-time) totalled 33, with 21 of these in professional / management positions. Two women were students in 
higher education. The remainder were home-makers or did voluntary work.

The mean length of time that respondents had been experiencing hot flushes was 4.8 years (range $<1-16$ years). Twelve of the sample were taking HRT (seven of these reported having had a hysterectomy). The sub-group taking HRT were continuing to experience hot flushes.

Thirty five women ( $81 \%$ sample) returned the 12 month follow-up questionnaire. As four of these were no longer experiencing hot flushes, the follow-up PCl measure was based on a sample of 31 .

\section{Questionnaire measures:}

The postal questionnaires gained extensive information about women's experiences of hot flushes. In addition to the information noted above, respondents were asked to provide an estimate of daily frequency of hot flushes recording over 12 hours. Psychological measures included the standardised Perceived Control over Hot Flushes Index (PCI); self-ratings of perceived control over physical onset of hot flushes, using a 0-100mm visual analogue scale (PCO); self-ratings of perceived control over feelings during hot flushes, using a $0-100 \mathrm{~mm}$ visual analogue scale (PCF); self-rated distress during hot flushes, using a 0-100mm visual analogue scale; standardised self-esteem scale (Rosenberg 1965). 
These measures were repeated in the 12-month follow-up questionnaire.

The $\mathrm{PCl}$ (Appendix 1) contained 9 items referring to positive control over flushing and 6 items referring to difficulties in control. For the latter, scoring was reversed so that higher scores reflected greater control. Wording was changed for item 14 . The original statement in the AHI referred to 'fate' but a pilot study revealed respondents' uncertainty about the meaning of this term. Reference instead to 'factors beyond control' was deemed more acceptable by respondents in the pilot study.

In order to compare the questionnaire scale measures with women's simple selfappraisal of control, visual analogue scales (VASs) were used. VASs are useful for indicating the intensity of feelings such as pain and distress (Huskisson 1974). Comparisons between VAS self-ratings and validated scales have been reported by Fisher \& Johnston (1996).

The self-ratings of perceived control were made on a $100 \mathrm{~mm}$ line, with anchor words "No control" and "Complete control". Respondents were asked "How much control (if any) do you have over when hot flushes occur? (PCO) and "How much control (if any) do you have over your feelings during hot flushes?" (PCF).

The following question was used to elicit self-ratings of distress: "Please indicate the amount of distress (if any) that you typically experience during a hot flush". Respondents were invited to place a mark on a $100 \mathrm{~mm}$ line with anchors marked "Not 
at all distressed" and "Extremely distressed".

Following Nicassio et al (1985), the Rosenberg self-esteem scale was also presented.

\section{RESULTS}

Five respondents overlooked one or more items within the Perceived Control Index so summary data (and correlations in Table 1) reflect a reduced sample of 38. The mean score on the perceived control index was 34.11 (standard deviation 6.74; minimum score 20; maximum score 48). Thus these scores reflected quite wide individual differences as expected.

\section{- Insert Table 1 here -}

Table 1 reports Spearman correlation coefficients. Perceived control (as measured by the standardised scale) was only weakly related to age and length of time that flushes had been experienced, with older women and/or those who had experienced flushes for longer scoring a little lower. Women who reported high numbers of daily flushes showed a significant tendency to regard themselves as lower in perceived control. More frequent flushes were also associated with higher self-rated distress $(r=0.421, p<$ $0.01)$.

The correlations showed that the Perceived Control Index (PCI) was related more strongly to simple self-ratings of perceived control over feelings during hot flushes, 
rather than perceived control over physical onset of flushes. Most women offered different ratings to the questions about control over flush onset and flush feelings. Flushes were mostly viewed as unpredictable, and control over flush onset was reported as low (about 11/100 on average). However, greater control was indicated concerning psychological responses to flush episodes (mean rating 44/100). The differentiation of responses provided some indication that women had found the selfrating task meaningful. Also of interest was the wide variation in PCF ratings, with some women apparently feeling helpless to modify their feelings during flushes (giving ratings as low as 2/100) whilst others expressed complete control (100/100).

$\mathrm{PCl}$ scores were moderately associated with self-esteem, although the relationship with self-esteem was of slightly lower magnitude than that noted by Nicassio et al (1985) in a sample of rheumatoid arthritis patients.

As expected from previous research, those higher in perceived control, as measured by the $\mathrm{PCl}$, viewed themselves as experiencing significantly less distress during hot flushes. As this could be partly accounted for by the tendency of less distressed women to be experiencing fewer flushes daily, a multiple regression analysis was carried out. When $\mathrm{PCl}$ and daily flush frequency were entered as predictors of distress, a significant proportion of variance was accounted for $(32.9 \%$; $F(2.35)=8.60 ; p<$ $0.001)$. However, $\mathrm{PCl}$ accounted for $28.4 \%$ of the variance in distress ratings $(\mathrm{t}(35)=$ $-2.82, p<0.008)$, and flush frequency did not significantly increase the proportion of variance accounted for $(t(35)=1.53, p=0.135)$. 
Over 12 months, PCl scores (among those still experiencing flushes) improved significantly but initial and follow-up scores were nevertheless highly correlated.

Although the three measures of perceived control (PCl, PCF, PCO) were significantly inter-correlated (Table 2), the $\mathrm{PCl}$ scores were generally more predictive of the other measured variables than simpler self-ratings of perceived control. Self-rated perceived control over physical occurrence of flushes had very little relationship with the other measured variables.

- Insert Table 2 here -

\section{DISCUSSION}

This study's findings suggested that the adapted AHI scale for measuring perceived control/helplessness was useful for studying psychological factors in hot flush distress, and that construct validity was indicated by the expected pattern of correlations, particularly with distress and self-esteem. The results showed that the $\mathrm{PCl}$, adapted from a validated scale, was significantly related to simple self-ratings of perceived control yet more predictive than the latter of flush distress.

As might be expected, there was a tendency for higher levels of distress during flushes 
to be reported by women who experienced more frequent flushing. However, low levels of perceived control were even more predictive of flush distress. Women who had lower self-esteem seemed to express somewhat greater helplessness in the face of menopausal flushes, but it is unclear from the correlational data whether menopausal flushing had challenged these women's sense of self-worth or whether women entering the menopause with lower self-esteem had fewer psychological resources for coping with flushing. These findings suggest a need for further investigation into whether coping with hot flushes may be enhanced by psychological interventions that attempt to increase perceived control and self-esteem.

The simpler self-ratings of perceived control (PCO/PCF) yielded an interesting distinction that has not apparently been explored in previous menopausal research. From their qualitative accounts (and in agreement with research by Gannon, Hansel \& Goodwin 1987), women commonly regarded the onset of a hot flush as either unpredictable, or triggered by stressful everyday events that were themselves difficult to control. For most, flushes simply 'happened' and PCO ratings were generally very low. However, women differed considerably in the extent to which they regarded themselves as having some control over psychological responses to hot flushes. Their qualitative descriptions of coping confirmed the self-ratings. Some described actively challenging their anxieties, irritation or embarrassment for example, whereas others felt psychologically trapped by flush sensations (and the burden of negative social attitudes). It was this latter form of helplessness over the subjective experience that was more predictive of distress during flushing. 
Perceived control improved significantly during the year of the study, although initial and follow-up scores were highly related to each other. The improvement is open to several interpretations. It is possible that flushes provoke less distress over time, as they subside (from the higher levels of the perimenopause) or simply as they become more familiar (Matthews 1992). However, this view is not supported by the relationships noted in Table 1 , which did not suggest general improvements in the sample in perceived control with increased age or more years of experience with flushing. It remains possible that the study itself may have had some influence during the twelve months between questionnaires. Perhaps participation in the extensive questionnaire study prompted self-reflection about coping and control, leading to experimentation with more varied coping strategies. Participation may also have encouraged some women to discuss flush problems and gain social support, increasing resources for coping. The potential role of research participation in raising awareness of psychological factors in health and enhancing coping strategies needs to be further explored.

It remains unclear why perceived control only accounted for a fairly small (albeit highly significant) proportion of the variance in self-rated distress during flushes. It is possible that flush discomfort varies in part according to flush 'severity' - as defined by frequency, intensity or duration of flush episodes. More detailed enquiry is needed concerning relationships between psychological variables such as control-helplessness and physiological aspects of flushing.

Flush discomfort may also be exacerbated by situational stressors, excluded from the 
present analysis. Respondents' qualitative accounts certainly suggest that the situation in which a flush occurs has a large impact both on level of distress and choice of coping strategies. The perceived control scale may be somewhat limited in its power to predict distress by not incorporating such situational factors and their impact on coping. There is also a need for further enquiry into relationships between perceived control and other psychological variables such as depression and health locus of control, as distress during flushes may reflect the woman's pre-existing vulnerability in managing stress.

The perceived control scale combines items referring both to control over the physical occurrence of flushes and also affective responses to flushing. As Nicassio et al (1985) also noted, these may represent different dimensions of control. Data from this study indicate that most women regard themselves as having little ability to control the onset of hot flushes. However, they vary much more in their perceived ability to control responses during flushes such as anxiety, embarrassment, loss of concentration and so on. Possibly the Perceived Control Index could be extended to measure more thoroughly control over the range of cognitive, affective and behavioural responses to flushing.

Acknowledgement must be made of the uncertain impact of having a small volunteer sample. Whilst the sample usefully disclosed a wide range of psychological responses to flushing, no automatic generalisation to a clinical sample should be made. Further work should address the reasons for the somewhat lower perceived control scores in the subsample taking HRT. Nevertheless, the correlates of the PCl indicate its 
potential usefulness in menopausal research and possibly in clinical settings to check the effectiveness of psychological approaches to managing flush distress.

\section{REFERENCES}

Ballinger, S.E. (1985) Psychosocial stress and symptoms of menopause: a comparative study of menopause clinic patients and non-patients. Maturitas, 7, 315327.

Coles, R.R.A. \& Hallam, R.S. (1987).Tinnitus and its management. British Medical Bulletin, 43, 983-998.

DeVellis, B.M. \& Blalock, S.J. (1992) Illness attributions and hopelessness depression: the role of hopelessness expectancy. Journal of Abnormal Psychology, 101, 257264.

Fisher, K. \& Johnston, M. (1996) Emotional distress as a mediator of the relationship between pain and disability: an experimental study. British Journal of Health Psychology, $\quad$ 1, 207-218.

Gannon, L., Hansel, S. \& Goodwin, J. (1987). Correlates of menopausal hot flushes. Journal of Behavioural Medicine, 10, 277-285.

Hammond, C.B. (1994) Women's concerns with hormone replacement therapy: compliance issues. Fertility and Sterility, 62, 157S-160S.

Hunter, M.S. (1989) Gynaecology. Ch 16 in Health Psychology: Processes and Applications, edited A. Broome. London: Chapman Hall. 
Hunter, M.S. (1990) Emotional well-being, sexual behaviour and hormone replacement therapy. Maturitas, 7, 299-314.

Hunter M.S. (1992) The SE England longitudinal study of the climacteric and postmenopause. Maturitas, 14, 117-126

Hunter, M.S. \& Liao, K.L. (1995) A psychological analysis of menopausal hot flushes. British Journal of Clinical Psychology, 34, 589-599.

Huskisson, E.C. (1974) Measurement of pain. Lancet, ii, 1127- 1131.

Keefe, F.J., Brown, G.K., Wallston, K.A., Caldwell, D. (1989) Coping with rheumatoid arthritis pain: catastrophising as a maladaptive strategy, Pain, 37, 51-56.

Kronenberg, F. (1990) Hot flashes: epidemiology and physiology. Annals of the New York Academy of Sciences, 592, 52-86.

Mansfield, P.K., Theisen, S.C., \& Boyer, B. (1992) Midlife women and menopause: a challenge for the mental health counsellor. Journal of Mental Health Counseling, 14, 73-83.

Matthews, K.A. (1992) Myths and realities of the menopause. Psychosomatic Medicine, 54, 1-9.

Morse, C.A., Smith, A., Dennerstein, L., Green, A., Hopper, J., $\quad$ \& Burger, $\quad$ H. (1994) The treatment -seeking woman at menopause. Maturitas, 18, 161-173.

Nicassio, P.M., Wallston, K.A., Callahan, L.F., Herbert, M., \& Pincus, T. (1985). The measurement of the helplessness in rheumatoid arthritis: the development of the arthritis helplessness index. Journal of Rheumatology, 12, 462-467.

Rosenberg, M. (1965). Society and the Adolescent Self-Image. Princeton: Princeton University Press.

Skinner, E.A. (1995) Perceived Control, Motivation and Coping. London: Sage. 
Smith, T.W., Christensen, A.J., Peck, J.R., Ward, J.R. (1994) Cognitive distortion, helplessness, and depressed mood in rheumatoid arthritis: a four-year longitudinal analysis. Health Psychology, 13, 213-217.

Tayer, W.G., Nicassio, P.M., Radojevic, V. \& Krall, T. (1996) Pain and helplessness as correlates of systemic lupus erythematosus. British Journal of Health Psychology, 1, 253- 262.

Ussher, J.M. (1989) The Psychology of the Female Body. London:Routledge.

Utian, W.H. (1990) The menopause in perspective: from potions to patches Annals of the New York Academy of Sciences, 592, 1-7.

Voda, A.M. (1981) Climacteric hot flush Maturitas, 3, 73-79.

Table 1: Means and standard deviations of study variables and Spearman correlations with Perceived Control Index scores

N Mean SD $\quad$ Correl

with $\mathrm{PCl}$

Age

43

51.2

5.67

$-0.19$

Flush frequency

43

9.7

8.44

$-0.43^{* *}$ 
Chronicity

Distress

PCO

PCF

Self-esteem

PCI(2)-12 month later

31

Key: ${ }^{* * *} p<0.001 ;{ }^{* *} p<0.01 ;{ }^{*} p<0.05$;

41

29.9

6.33

$0.32^{*}$

43

43

44.5

32.46

$0.63^{* * *}$

$14.55 \quad 0.44^{* *}$

except for the correlation between $\mathrm{PCl}(1)$ and $\mathrm{PCl}(2)$ where $\mathrm{N}=31$

Table 2: Correlations between perceived control measures (PCI,PCF,PCO), and self-reported flush distress, flush frequency, flush chronicity, self-esteem (Spearman test).

$\begin{array}{lll}\mathrm{PCl} & \mathrm{PCF} & \mathrm{PCO} \\ (\mathrm{N}=38) & (\mathrm{N}=43) & (\mathrm{N}=43)\end{array}$

Flush distress

$\begin{array}{lll}-0.53^{* * *} & -0.31^{*} \quad-0.01\end{array}$




\section{APPENDIX 1: Perceived Control over Hot Flushes Index}

(based on the original scale of Nicassio et al 1985)

Please indicate your level of agreement or disagreement with each statement on the following scale, by circling the appropriate number next to each statement:

1

Strongly

Disagree

Disagree

2
3

Agree

Strongly

Agree

1. Hot flushes are controlling my life

1234 
2. It is largely my own responsibility to manage my hot flushes

3. I can reduce my distress during hot flushes by remaining calm and relaxed

4. Too often, a hot flush just seems to hit me out of the blue

5. If I do all the right things, I can successfully manage hot flush symptoms

6. I can do a lot of things myself to cope with my hot flushes

7. When it comes to managing my hot flushes, I feel I can only do what my doctor tells me to do.

8. When I manage my personal life well, my hot flushes do not flare up so much.

9. I have considerable ability to control 
10. I rely on other people to help me cope with my hot flushes

11. Usually I can tell the days when my hot flushes are going to flare up

12. No matter what I do or how hard I try, I just can't seem to get any relief from hot flushes

13. I am coping effectively with my hot flushes

14. It seems as though factors beyond my control affect my hot flushes

15. I want to learn as much as I can about hot flushes and the menopause 